\title{
Development and optimisation of a sex pheromone lure for monitoring populations of saddle gall midge, Haplodiplosis marginata
}

\author{
Charlotte Rowley ${ }^{1 *}$ (D), Tom W. Pope ${ }^{1}$, Andrew Cherrill ${ }^{1}$, Simon R. Leather ${ }^{1}$, \\ G. Mandela Fernández-Grandon ${ }^{2}$ \& David R. Hall ${ }^{2}$ \\ ${ }^{1}$ Centre for Integrated Pest Management, Harper Adams University, Newport, Shropshire TF10 8NB, UK, and ${ }^{2}$ Natural \\ Resources Institute, University of Greenwich, Chatham Maritime, Kent ME4 4TB, UK
}

Key words: (R)-2-nonyl butyrate, chirality, wheat, traps, dispensers, electroantennography, Diptera, Cecidomyiidae, EAG

\begin{abstract}
Saddle gall midge, Haplodiplosis marginata (von Roser) (Diptera: Cecidomyiidae), is a sporadic pest of cereals in Northern and Central Europe and is of increasing importance in the UK. Recently, the major component of the sex pheromone produced by adult female $H$. marginata was reported to be 2-nonyl butyrate. The importance of absolute configuration on attractiveness, the effects on trap catches of the addition of minor pheromone components, dispenser type, and pheromone loading are described in the development of an optimised pheromone lure with which to trap $H$. marginata males. In analyses of volatiles collected from virgin female $H$. marginata by gas chromatography (GC) coupled with electroantennographic recording (EAG) from the antenna of a male H. marginata, two EAG responses were observed. Analyses by coupled GC-mass spectrometry (MS) indicated these were due to 2-nonyl butyrate and a trace amount (1\%) of 2-heptyl butyrate. A similar trace amount of 2-nonanol was detected in GC-MS analyses but this compound did not elicit an EAG response when the synthetic compound was tested, whereas the other two compounds did. These three compounds were not observed in collections of volatiles made from male H. marginata. The 2-nonyl butyrate was shown to be the $(R)$-enantiomer. In field trapping tests $(R)$-2-nonyl butyrate was at least $10 \times$ more attractive to male $H$. marginata than the racemic compound, and the $(S)$ enantiomer was unattractive. Addition of the potential minor components individually or together at the naturally occurring ratios did not increase or reduce the attractiveness of the lure. Polyethylene vials and rubber septa were equally effective as pheromone dispensers, lasting for at least 5 weeks in the field in the UK, although laboratory tests indicated release from the former was more uniform and more likely to last longer in the field. Increasing loading of pheromone in the dispenser increased attractiveness. Traps baited with polyethylene vials containing $0.5 \mathrm{mg}$ of $(R)$-2-nonyl butyrate are recommended for monitoring $H$. marginata and these are far more sensitive than water or sticky traps currently used for monitoring this pest.
\end{abstract}

\section{Introduction}

Saddle gall midge, Haplodiplosis marginata (von Roser) (Diptera: Cecidomyiidae), is a sporadic pest of cereals of increasing importance in the UK and parts of continental

*Correspondence: Charlotte Rowley, Centre for Integrated Pest Management, Harper Adams University, Newport, Shropshire TF10 8NB, UK. E-mail: crowley@harper-adams.ac.uk
Europe. Yield losses of up to 70\% have been reported during recent UK outbreaks (Ellis et al., 2014). It is a univoltine species with a short-lived adult stage and an overwintering phase in the larval stage. Adults begin emerging around the start of May (Skuhravý et al., 1983; Gratwick, 1992) and mating occurs immediately (Golightly \& Woodville, 1974). Females lay their eggs on the leaves of cereals and other grasses and, once hatched, the larvae begin feeding on the stem of the host plant resulting in the formation of saddle-shaped galls beneath 
the leaf sheath (Skuhravý et al., 1983; Dewar, 2012). Gall formation can damage the plant by restricting nutrient flow to the ear leading to under-filled grains, and by leaving the plant vulnerable to attack from secondary pathogens (Nijveldt \& Hulshoff, 1968; Dewar, 2012). Severe infestation results in multiple galls along the stems of a cereal plant, weakening the stems and increasing the risk of stem breakage which can cause substantial yield loss (Gratwick, 1992; Berry et al., 1998). Crops most at risk from $H$. marginata are spring wheat, barley, and late-sown winter wheat, particularly in areas with heavy soils (Golightly \& Woodville, 1974; Skuhravý et al., 1983, 1993; Pope \& Ellis, 2013).

The pest is very sporadic and the exact conditions which influence diapause termination, emergence, and the reproductive success of $H$. marginata are unknown, making outbreaks difficult to forecast (Woodville, 1973; Basedow, 1986). As in other Cecidomyiidae, monitoring populations of $H$. marginata is difficult due its cryptic nature (Harris \& Foster, 1999). Additionally the timing of pesticide application is critical as once the larvae begin feeding they are protected from contact insecticides by the leaf sheath. The best control is achieved when sprays coincide with the first appearance of adults or eggs in the crop, or 7-10 days after the start of adult emergence (Ellis et al., 2014). Consequently, there is an urgent need for a simple and effective monitoring system for growers to use and on which pest management decisions can be based (Censier et al., 2015, 2016b).

Monitoring of pest populations allows insecticides to be applied judiciously to target the temporal occurrence of the vulnerable life-stage of the organism (Jones, 1998). Use of pheromone-baited traps has been found to be an effective method of population monitoring in many pest species (Hardie \& Minks, 1999; Witzgall et al., 2010), including a related cecidomyiid species, the orange wheat blossom midge, Sitodiplosis mosellana (Gehin) (Bruce et al., 2007; Bruce \& Smart, 2009; Oakley \& Ellis, 2009).

The major component of the $H$. marginata sex pheromone was recently identified as 2-nonyl butyrate and the synthetic racemic compound was found to be attractive to male insects in field trials in Belgium (Censier et al., 2014, 2016a). In our work we confirmed the basic findings of Censier et al. (2014) and extended them by using electroantennography (EAG) to detect potential minor pheromone components. The effects of these were evaluated in field trapping tests, as was the importance of the absolute configuration of the major pheromone component and the effect of pheromone loading on trap catches. Practical pheromone dispensers were evaluated to provide farmers and agronomists with an effective monitoring system on which to base pest management decisions.

\section{Materials and methods}

Insects

Larvae of $H$. marginata were collected from soil samples taken from affected fields between November 2013 and May 2014 and stored at $4{ }^{\circ} \mathrm{C}$ for a minimum of 3 months. Each larva was transferred to an individual plastic container $(1.5 \mathrm{~cm}$ diameter, $2.5 \mathrm{~cm}$ high) of moist sterilised compost covered with a fine mesh and maintained at $20^{\circ} \mathrm{C}, 60 \%$ r.h., and L16:D8 photoperiod, until adults emerged.

\section{Pheromone collection}

Volatiles were collected from individual virgin adult males and females separately, within $48 \mathrm{~h}$ of emergence. A single live midge was used per collection and was placed in a cylindrical glass vessel $(5.3 \mathrm{~cm}$ diameter, $13 \mathrm{~cm}$ long; Hamilton Laboratory Glass, Margate, UK) with a glass frit and activated charcoal filter at one end $(20 \times 2 \mathrm{~cm}, 10$ 18 mesh; Fisher Chemicals, Loughborough, UK) and a collection filter at the other. The collection filter consisted of a Pasteur pipette $(4 \mathrm{~mm}$ i.d.) containing Porapak Q (200 mg, 80-100 $\mu \mathrm{m}$; Waters Associates, Milford, MA, USA) positioned between two glass wool plugs (Supelco, Gillingham, Dorset, UK). Air was drawn through the charcoal filter into the vessel containing the midge and out through the collection filter using a vacuum pump (M361C; Charles Austen Pump, Byfleet, UK) at a rate of 0.51 per min. Collections were made continuously for a period of $48 \mathrm{~h}$. Five collections were made from males and four from females. Volatiles were desorbed from the collection filters with dichloromethane $(1.5 \mathrm{ml})$, concentrated under a stream of nitrogen, and refrigerated prior to analysis.

\section{Coupled gas chromatography-mass spectrometry (GC-MS)}

Aliquots of volatile collections were analysed using a Varian 3500 GC coupled with a Saturn 2200 MS (Agilent Technologies, Stockport, UK) operated in electron impact mode. A polar or non-polar GC column was used (30 m $\times 0.25 \mathrm{~mm}$ i.d., $0.25 \mu \mathrm{m}$ film thickness) coated with DBWax (Supelco) or VF5 (Agilent), respectively, and the oven temperature was held at $40{ }^{\circ} \mathrm{C}$ for $2 \mathrm{~min}$ and then programmed at $10^{\circ} \mathrm{C}$ per min to $240{ }^{\circ} \mathrm{C}$. Compounds were identified by their mass spectra, their GC retention indices relative to the retention times of $n$-alkanes and comparison of retention indices and mass spectra with those of authentic synthetic standards.

Coupled gas chromatography-electroantennography (GC-EAG)

Antennal responses of male and female $H$. marginata to collections of volatiles from females were measured by 
EAG coupled with an Agilent 6890N GC with fused silica capillary columns $(30 \mathrm{~m} \times 0.32 \mathrm{~mm}$ i.d., $0.25 \mu \mathrm{m}$ film thickness) coated with polar DB Wax (Agilent) and nonpolar SPB1 (Supelco). Injections were splitless $\left(220^{\circ} \mathrm{C}\right.$ ) for the polar column and with programmed temperature vaporising injector (held at $50{ }^{\circ} \mathrm{C}$ for $0.2 \mathrm{~min}$ and then programmed at $600{ }^{\circ} \mathrm{C}$ per min to $220^{\circ} \mathrm{C}$ ) for the nonpolar column. The carrier gas was helium $(2.4 \mathrm{ml}$ per min) and the oven temperature was held at $50{ }^{\circ} \mathrm{C}$ for 2 min and then programmed at $10{ }^{\circ} \mathrm{C}$ per min to $250{ }^{\circ} \mathrm{C}$. The ends of the GC columns went into a push-fit Y-connecter that lead through a second Y-connector fitted with two equal lengths of deactivated fused silica capillary going to the flame ionisation detector (FID) and a glass T-piece, splitting the GC effluent 50:50. The effluent was collected in the T-piece for $17 \mathrm{~s}$ before being blown over the antennal preparation for $3 \mathrm{~s}$ in a stream of air $(200 \mathrm{ml}$ per min) (Cork et al., 1990).

The antennae were prepared by excising the head from a live specimen, then removing one of the antennae and the tip of the remaining antenna using a sharp microscalpel. Antennal responses were recorded using an INR-2 micromanipulator assembly (Syntech, Hilversum, The Netherlands). Two newly pulled glass capillary electrodes were filled with an electrolyte solution of $0.1 \mathrm{M} \mathrm{KCl}$ with $1 \%$ polyvinylpyrrolidine (BDH Chemicals, Poole, UK) added to prevent evaporation. These were attached to silver wire electrodes mounted in micromanipulators. The insect preparation was mounted between the two glass electrodes with the head in the reference electrode and the distal end of the antenna in the recording electrode. The antennal responses were amplified $10 \times$ and converted to digital format through the second detector channel of the GC. Data from FID and EAG were captured and processed with EZChrom Elite v.3.3.1 software (Agilent).

\section{Enantioselective gas chromatography}

Enantoselective GC was carried out on a CP-Chirasil-Dex $\mathrm{CB}$ column $(25 \mathrm{~m} \times 0.32 \mathrm{~mm}$ i.d., $0.25 \mu \mathrm{m}$ film thickness; Varian/Agilent) with He carrier gas ( $2.4 \mathrm{ml}$ per min), split injection $\left(220^{\circ} \mathrm{C}, 20: 1\right)$, and FID $\left(220^{\circ} \mathrm{C}\right)$. The oven temperature was held at $60{ }^{\circ} \mathrm{C}$ for $2 \mathrm{~min}$ and then programmed to increase with $5{ }^{\circ} \mathrm{C}$ per min to $200{ }^{\circ} \mathrm{C}$.

\section{Chemicals}

Unless otherwise stated, all chemicals were obtained from SigmaAldrich (Gillingham, Dorset, UK) and were at least 98\% pure. Racemic 2-nonyl butyrate was prepared by esterification of 2-nonanol with butyric acid in the presence of $\mathrm{N}, \mathrm{N}^{\prime}$-dicyclohexylcarbodiimide (DCCD) and 4dimethylamino-pyridine (DMAP) in dichloromethane (Neises \& Steglich, 1978). The product was obtained in
93\% yield after purification by flash chromatography on silica gel eluted with $2 \%$ diethyl ether in hexane and kugelrohr distillation (at $70{ }^{\circ} \mathrm{C}$ and $0.03 \mathrm{~mm} \mathrm{Hg}$ ). ${ }^{1} \mathrm{H}$ and ${ }^{13} \mathrm{C}$ nuclear magnetic resonance (NMR), infrared (IR), and mass spectral (MS) data were in agreement with those reported by Censier et al. (2014).

Racemic 2-nonyl butyrate was resolved into the two enantiomers by stirring with a catalytic amount of lipase acrylic resin from Candida antarctica yeast in phosphate buffer $\left(1 \mathrm{M} \mathrm{K}_{2} \mathrm{HPO}_{4}\right)$ for $6 \mathrm{~h}$ with monitoring by enantioselective GC, which selectively hydrolysed the $(R)$-enantiomer (Hall et al., 2012). The product was chromatographed on silica gel eluted successively with 2 , $5,10,20$, and $50 \%$ diethyl ether in hexane to give $(S)-2$ nonyl butyrate $(98.7 \%$ enantiomeric excess by enantioselective GC) and ( $R$ )-2-nonanol. The latter was esterified as above to give $(R)-2$-nonyl butyrate ( $98.9 \%$ e.e.).

Racemic 2-heptyl butyrate was prepared similarly from 2-heptanol. This was resolved into the enantiomers with lipase from $C$. antarctica to give the $(S)-(97.8 \%$ e.e. $)$ and $(R)-(98.2 \%$ e.e.) enantiomers.

\section{Pheromone dispensers}

Two different dispenser types were tested: polyethylene vials $(26 \times 8 \mathrm{~mm}, 1.5 \mathrm{~mm}$ thick; Just Plastics, London, $\mathrm{UK})$ and white rubber septa $(20 \times 10 \mathrm{~mm}$; International Pheromone Systems, The Wirral, UK). These were loaded with the pheromone dissolved in hexane $(100 \mu \mathrm{l})$ and the solvent was allowed to evaporate.

Release rates were measured for dispensers loaded with 2-nonyl butyrate $(1 \mathrm{mg})$ and maintained in a laboratory wind tunnel $\left(27^{\circ} \mathrm{C}, 2.2 \mathrm{~m} \mathrm{~s}^{-1}\right.$ wind speed $)$. Duplicate samples were removed at weekly intervals and the remaining pheromone was extracted individually in hexane $(5 \mathrm{ml})$ containing dodecyl acetate $(1 \mathrm{mg})$ as internal standard. Extracts were analysed by GC with FID on a capillary column $(30 \mathrm{~m} \times 0.32 \mathrm{~mm}$ i.d., $0.125 \mu \mathrm{m}$ film thickness) coated with DB5 (Agilent) with splitless injection $\left(220^{\circ} \mathrm{C}\right)$ and the oven temperature held at $50{ }^{\circ} \mathrm{C}$ for $2 \mathrm{~min}$ and then programmed at $10{ }^{\circ} \mathrm{C}$ per min to $250{ }^{\circ} \mathrm{C}$. The amount of pheromone remaining in lures returned from field trapping tests was measured similarly.

\section{Field trapping experiments}

Field trapping experiments were all carried out at sites with known soil populations of $H$. marginata. Five experiments were performed. Experiments 1, 2, 3, and 4 were carried out in Oxfordshire, UK $\left(51^{\circ} 55^{\prime \prime} \mathrm{N}, 1^{\circ} 10^{\prime \prime} \mathrm{W}\right)$. Experiment 5 was carried out in Buckinghamshire, UK $\left(51^{\circ} 37^{\prime \prime} \mathrm{N}, 0^{\circ} 48^{\prime \prime}\right.$ $W)$. All fields were in winter wheat and the experiments were conducted during part of the flight season of 
H. marginata, coinciding with wheat growth stages 39-59 (Zadoks et al., 1974).

For each experiment, pheromone dispensers were placed in standard red delta traps (Agralan, Wiltshire, UK) containing a removable sticky insert $(15 \times 15 \mathrm{~cm})$. Polyethylene vials were used as dispensers for all experiments with the exception of experiment 1 . Traps were hung from fibreglass canes and positioned at the height of the wheat ear. For experiments 1-4, traps were laid out in a randomised complete block design with $10 \mathrm{~m}$ between traps and $50 \mathrm{~m}$ between blocks. Adult $H$. marginata were identified based on antennal and genital morphology (Harris, 1966) and counted using a bifocal microscope.

Experiment 1 - Pheromone dispensers. Catches of male H. marginata in traps baited with racemic 2-nonyl butyrate $(1 \mathrm{mg})$ formulated in the two types of pheromone dispenser, rubber septa, and polyethylene vials, were compared with catches in an unbaited trap. Traps were laid out in four replicated blocks and were in place between 15 May and 19 June 2014 and the sticky inserts of the traps were changed after 6 days, at which time the treatments were re-randomised within the blocks.

Experiment 2 - Pheromone chirality. Catches in traps baited with lures containing $(R)$-2-nonyl butyrate (0.5 mg), (S)-2-nonyl butyrate $(0.5 \mathrm{mg})$, the racemic mixture $(1 \mathrm{mg})$, and an unbaited trap as control were compared. Traps were laid out in four replicated blocks and were in place between 5 and 19 June 2014.

Experiment 3 - Effect of minor components. The effects of addition to $(R)$-2-nonyl butyrate $(0.5 \mathrm{mg})$ of two minor components were tested: $(R)$-2-nonanol and $(R)$-2-heptyl butyrate, each at $2 \%$ of the major component, separately and in combination. These treatments were compared with lures containing $(R)$-2-nonyl butyrate $(0.5 \mathrm{mg})$, lures containing the racemic mixture $(1 \mathrm{mg})$, and with an unbaited trap as control. Traps were laid out in 10 replicated blocks and were in place between 18 and 29 May 2015. The sticky inserts of the traps were changed on days 4 and 9 of the experiment, with the treatments rerandomised within the blocks after each change.

Experiment 4 - Pheromone loading. Trap catches with lures containing loadings of 2.5, 0.5, 0.05, and $0.005 \mathrm{mg}$ of the major pheromone component, $(R)$-2-nonyl butyrate, were compared. Traps were laid out in 10 replicated blocks and were in place between 2 and 11 June 2015. The sticky inserts of the traps were changed on days 4 and 8 of the experiment, with the treatments re-randomised within the blocks after each change.
Experiment 5 - Comparison with other traps. Numbers of midges caught in delta traps baited with lures containing (R)-2-nonyl butyrate $(0.5 \mathrm{mg})$ were compared with existing trapping methods, that is, unbaited sticky traps and water traps. Standard yellow insect sticky traps $(25 \times 10 \mathrm{~cm})$ were mounted on fibreglass canes at crop height. Water traps (Nickerson Brothers, Lincoln, UK) comprised a yellow bowl (25 cm diameter, $10 \mathrm{~cm}$ deep), partly filled with water to which several drops of Fairy dishwashing liquid were added, and mounted on a cane at crop height. All three traps were compared in two $3 \times 3$ Latin squares. All traps were checked at weekly intervals between 11 and 29 May 2015.

\section{Statistical analysis}

Numbers of $H$. marginata caught per day for each trap were $\log (\mathrm{x}+1)$ transformed to improve the homoscedasticity of the data and were analysed with a two-way ANOVA with treatment and block as factors. The least significant difference (LSD) test was used to test for significant differences between means $(\alpha=0.05)$. All analyses were done in R v.3.2.2 (R Core Team, 2015). Results in experiment 5 were not analysed statistically due to the extreme heteroscedasticity of the data.

\section{Results}

\section{Pheromone identification}

Analyses of collections of volatiles from female $H$. marginata on the non-polar GC column with a male antenna EAG preparation indicated one strong EAG response and a weaker response to a compound eluting earlier (Figure 1). Analyses on the polar column showed a strong EAG response but the minor response was not so clear (data not shown). Retention data for the EAG responses and synthetic compounds are shown in Table 1.

Analyses of collections of volatiles from female and male H. marginata by GC-MS on both non-polar and polar GC columns (Figure 2) indicated a female-specific compound that was identified as 2-nonyl butyrate by comparison of retention times (Table 1) and mass spectrum with those of the authentic synthetic compound, and the identification was confirmed by co-chromatography on both GC columns. Up to $50 \mathrm{ng}$ per female of 2-nonyl butyrate was collected during $48 \mathrm{~h}$. This compound had retention data consistent with that of the major response in the GC-EAG analyses (Table 1).

2-Nonanol was detected in GC-MS analyses at ca. $2 \%$ of the 2-nonyl butyrate. Single ion scanning of the GC-MS analyses of volatiles from female $H$. marginata at $\mathrm{m} / \mathrm{z} 71$ and 89 , characteristic of butyrate esters, showed the presence of 2-heptyl butyrate at ca. $1 \%$ of 
Figure 1 Coupled gas chromatographyelectroantennography (GC-EAG) analysis of collection of volatiles from female Haplodiplosis marginata on non-polar column. Note that the lower panel is an expansion of the upper panel and FID signal is lower trace and EAG upper trace in each; major response (1) to 2-nonyl butyrate at $12.42 \mathrm{~min}$, minor response (2) at $10.2 \mathrm{~min}$; 2-heptyl butyrate at $10.00 \mathrm{~min}, 2$-nonanol at $8.25 \mathrm{~min}$.
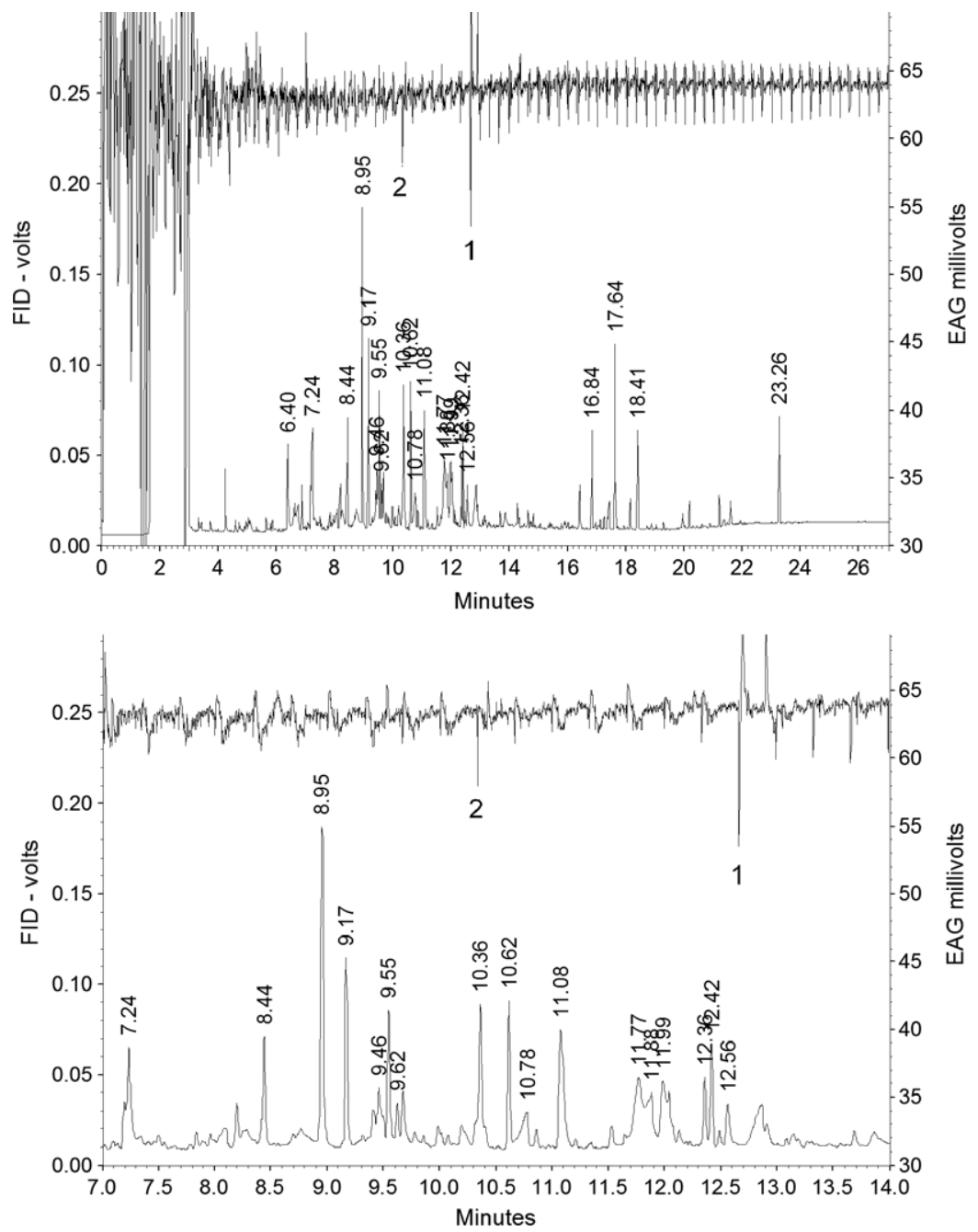

the 2-nonyl butyrate. 2-Undecyl butyrate, an analogue reported to be present by Censier et al. (2014), could not be detected $(<0.1 \%$ of major component). Similarly, 2,7-dibutyroxynonane, the female sex pheromone of the closely related orange wheat blossom midge, S. mosellana (Gries et al., 2000), could not be detected by comparison with the authentic synthetic compound. Other potential minor pheromone components related to 2-nonyl butyrate, such as 2-nonanone and 2-nonyl acetate, could not be detected (Table 1).

In GC-EAG analyses of the synthetic compounds (10 ng injected), strong EAG responses were observed to 2-nonyl butyrate and 2-heptyl butyrate, but there was no detectable response to 2-nonanol (data not shown). The retention indices of 2-heptyl butyrate were consistent with those of the component responsible for the minor EAG responses in analyses of volatiles from female midges on both non-polar and GC columns in the GC-EAG system used (Table 1).

Analysis of the volatiles from female H. marginata on the enantioselective cyclodextrin GC column indicated a peak at the retention time of $(R)$-2-nonyl butyrate $(15.69 \mathrm{~min})$, but no peak $(<5 \%)$ at the retention time of the $(S)$-enantiomer (15.30 min).

\section{Pheromone dispensers}

Polyethylene vials were found to release 2-nonyl butyrate more uniformly than the rubber septa under laboratory conditions (Figure 3). The rubber septa released over $90 \%$ of the pheromone within the 1 st week at $27^{\circ} \mathrm{C}$ and $2.2 \mathrm{~m} \mathrm{~s}^{-1}$ wind speed. In contrast, $30 \%$ of the compound remained after 28 days in the polyethylene vials.

Polyethylene vials containing an initial loading of $1 \mathrm{mg}$ racemic 2-nonyl butyrate and returned from field tests 
Table 1 Retention indices relative to retention times of $n$-alkanes of electroantennography (EAG) responses in gas chromatography (GC)-EAG analyses of volatiles from virgin female Haplodiplosis marginata with male H. marginata EAG preparation, and of synthetic compounds

\begin{tabular}{|c|c|c|c|c|}
\hline & \multicolumn{2}{|l|}{ Non-polar } & \multicolumn{2}{|l|}{ Polar } \\
\hline & GC-EAG $(\mathrm{SPB} 1)^{1}$ & GC-MS (VF5) ${ }^{1}$ & GC-EAG $(\text { DBWax })^{1}$ & GC-MS (DBWax) ${ }^{1}$ \\
\hline EAG major & 1389 & & 1601 & \\
\hline EAG minor & 1235 & & 1415 & \\
\hline 2-Nonyl butyrate & 1389 & 1403 & 1601 & 1591 \\
\hline 2-Nonanol & 1082 & 1104 & 1528 & 1513 \\
\hline 2-Nonyl acetate & 1218 & 1234 & 1460 & 1456 \\
\hline 2-Heptyl butyrate & 1201 & 1215 & 1400 & 1392 \\
\hline 2,7-Dibutyroxy-nonane & 1846 & 1861 & 2282 & 2245 \\
\hline 2-Nonanone & 1075 & 1092 & 1376 & 1378 \\
\hline
\end{tabular}

${ }^{1} \mathrm{GC}$ column phase.
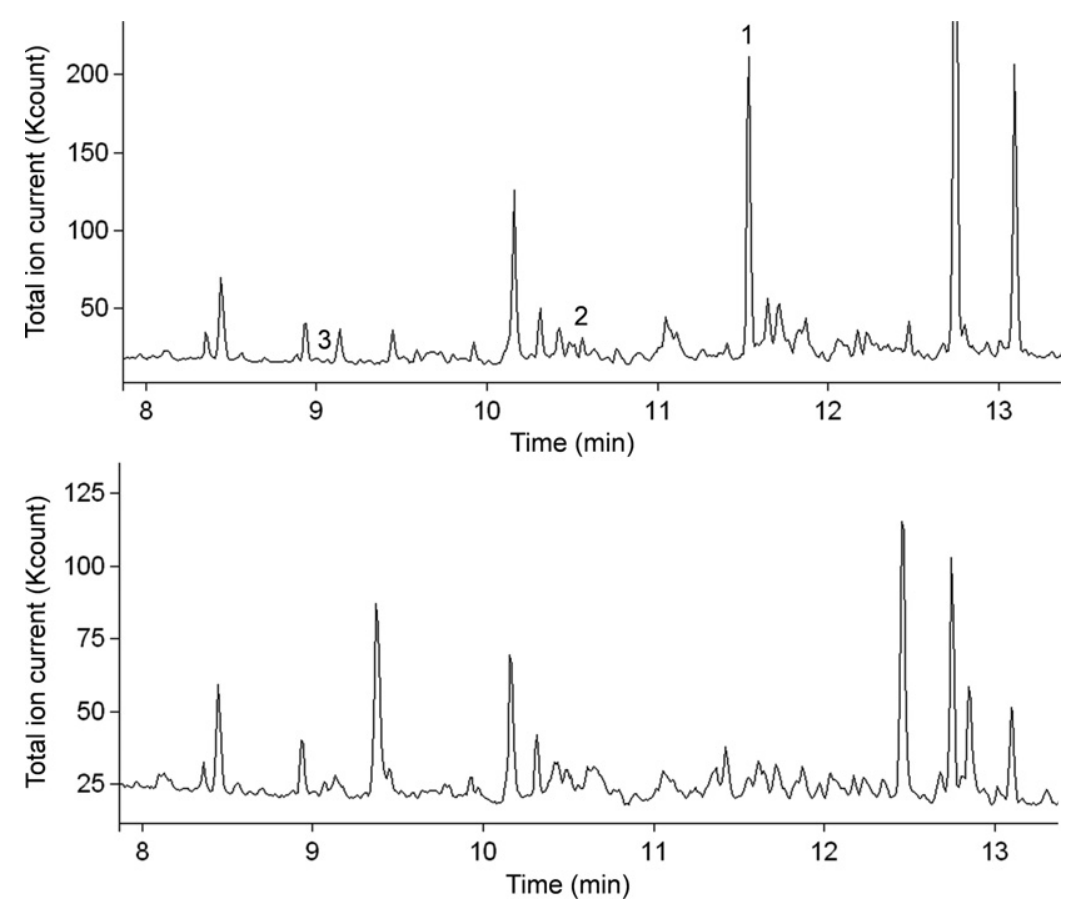

Figure 2 Coupled gas chromatographymass spectrometry (GC-MS) analyses on polar GC column of volatiles from female Haplodiplosis marginata (upper panel) and volatiles from male $H$. marginata (lower panel). (1) 2-Nonylbutyrate, (2) 2-nonanol, (3) 2-heptyl butyrate.

after 2 weeks contained (mean $\pm \mathrm{SEM}=$ ) $0.72 \pm 0.02 \mathrm{mg}$ $(n=3)$. Polyethylene vials and rubber septa returned from the field after 6 weeks contained $0.41 \pm 0.02$ and $0.31 \pm 0.02 \mathrm{mg}$, respectively.

\section{Field trapping experiments}

Experiment 1 - Pheromone dispensers. Traps baited with $1 \mathrm{mg}$ racemic 2-nonyl butyrate dispensed from either rubber septa or polyethylene vials caught more male $H$. marginata than the unbaited traps at site 2 in winter wheat $\left(\mathrm{F}_{2,9}=21.33, \mathrm{P}<0.001\right)$ during the 1 st week of trapping. However, there was no difference in catches with the two dispenser types (Figure 4A). Catches during the next 2 weeks were too low for analysis but showed the same trend with mean catches per trap over the period of $4.3 \pm 1.9$ with vials, $5.3 \pm 1.4$ with septa, and no catches in unbaited traps.

Experiment 2 - Pheromone chirality. Traps baited with (R)-2-nonyl butyrate caught significantly more male $H$. marginata compared to the other treatments $\left(\mathrm{F}_{3,9}=\right.$ 22.56, $\mathrm{P}<0.001)$. During the 14 -day trapping period no 
Figure 3 Release of 2-nonyl butyrate (1 mg) from rubber septa and polyethylene vials in laboratory wind tunnel at $27^{\circ} \mathrm{C}$ and $2.2 \mathrm{~m} \mathrm{~s}^{-1}$ wind speed as measured by gas chromatography analyses of the amount remaining at intervals.

Figure 4 Mean ( \pm SEM) daily catches of male Haplodiplosis marginata in traps baited with (A) racemic 2-nonyl butyrate (1 mg) dispensed from polyethylene vials or rubber septa (experiment 1, 15-21 May 2014); (B) racemic 2-nonyl butyrate (1 mg), (R)-2-nonyl butyrate (0.5 mg), (S)-2-nonyl butyrate $(0.5 \mathrm{mg})$, and unbaited (experiment 2, 5-19 June 2014); and $(C)$ a range of treatments (experiment 3, 18-29 May 2015): A, 0.5 mg (R)-2nonyl butyrate; $\mathrm{B}, 0.5 \mathrm{mg}(R)$-2-nonyl butyrate $+2 \%(R)$-2-nonanol; C, $0.5 \mathrm{mg}$ $(R)-2$ nonyl butyrate $+2 \%(R)-2$ heptyl butyrate; $\mathrm{D}, 0.5 \mathrm{mg}(R)$-2-nonyl butyrate $+2 \%(R)$-2-nonanol $+2 \%(R)$ 2 heptyl butyrate; E, $1 \mathrm{mg}$ racemic 2-nonyl butyrate; F, unbaited control. Bars show back-transformed means. Means within a panel capped with different letters are significantly different [LSD tests: $\mathrm{P}<0.001$ (panels A and B), $\mathrm{P}<0.05$ (panel C)].
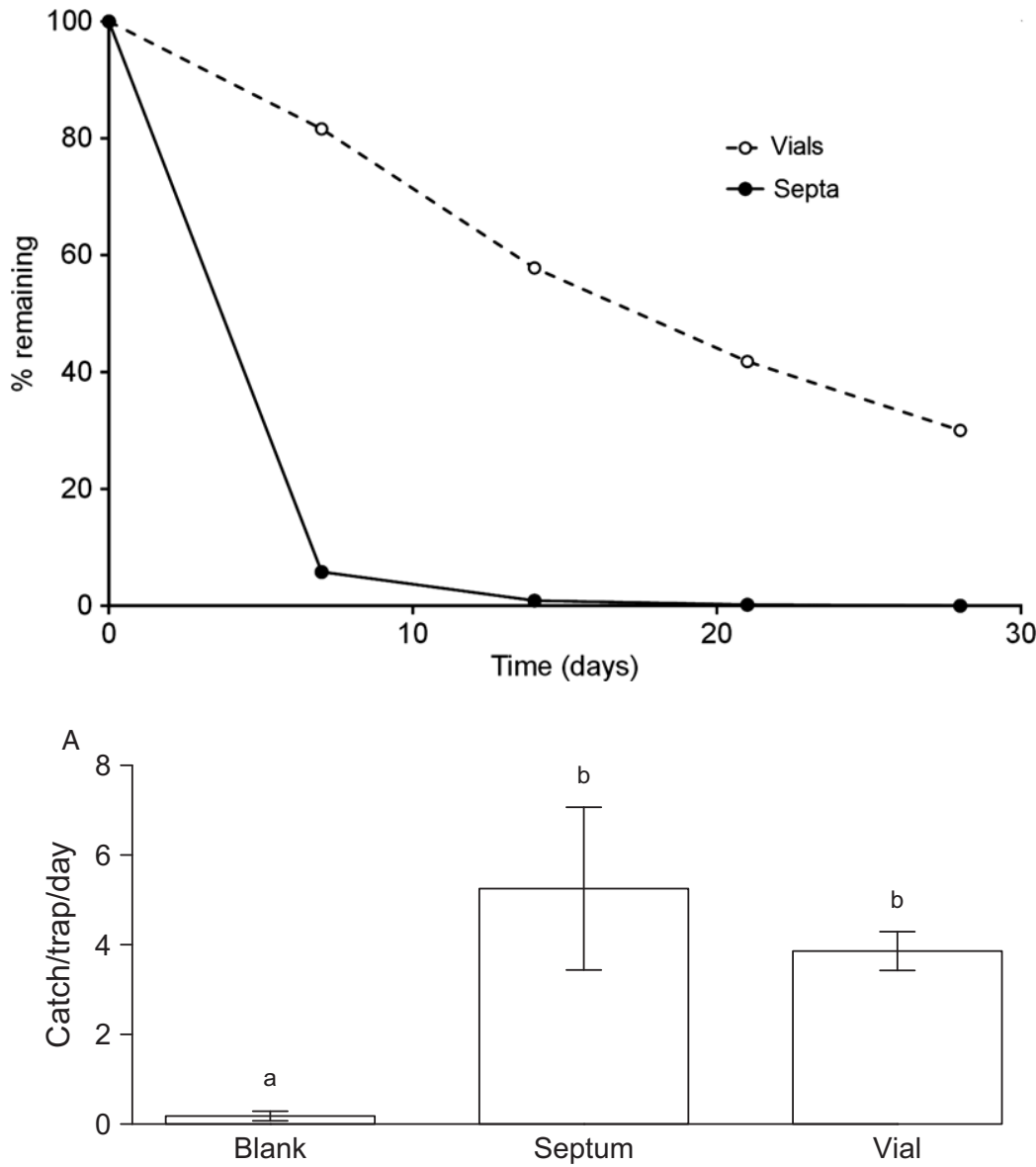

B

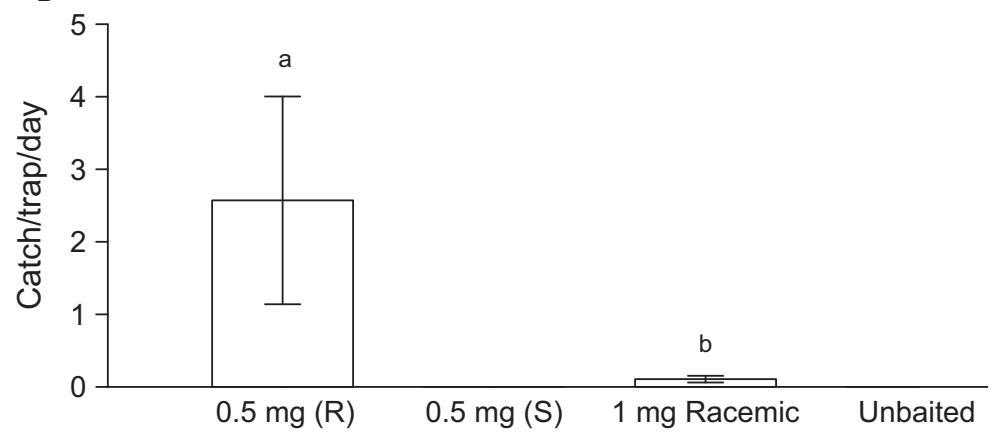

C

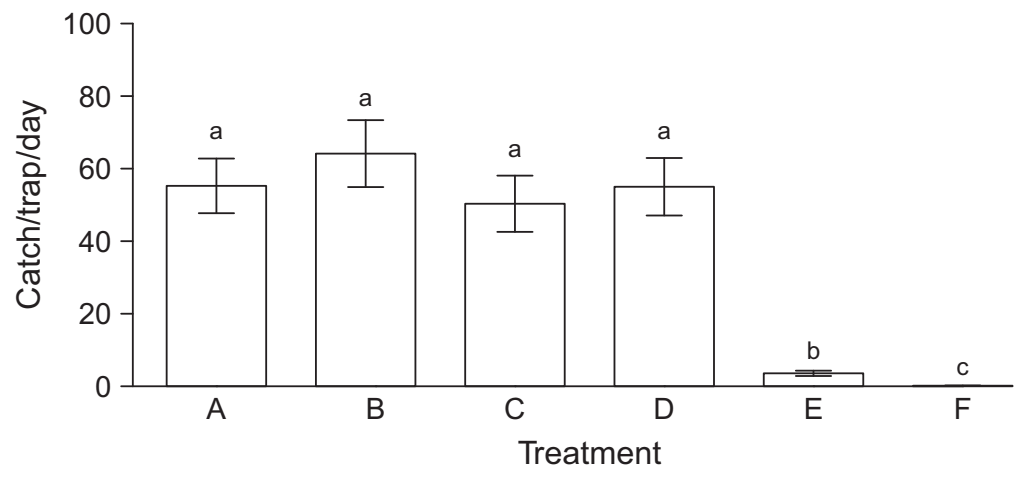


adults were caught on the unbaited traps or the traps baited with (S)-2-nonyl butyrate, and the catch with racemic 2-nonyl butyrate was less than $5 \%$ of that with (R)-2-nonyl butyrate (Figure 4B).

Experiment 3 - Effect of minor components. A total of 26658 male $H$. marginata was caught during the 11-day trapping period. Traps baited with racemic 2-nonyl butyrate caught significantly more than unbaited traps but less than $10 \%$ of the number caught in traps baited with $(R)$-2-nonyl butyrate $\left(\mathrm{F}_{5,45}=253.66, \mathrm{P}<0.001\right.$; Figure 4C). Addition of the minor components, $(R)-2$ nonanol and/or $(R)$-2-heptyl butyrate, did not increase or decrease trap catches compared with catches with the major component, $(R)$-2-nonyl butyrate, alone. There was no interaction between treatment and block but the effect of block was significant $\left(\mathrm{F}_{9,45}=6.799, \mathrm{P}<0.01\right)$.

Experiment 4-Pheromone loading. A total of 13775 male H. marginata were caught during the 9-day trapping period. Significant differences in numbers caught were observed between all treatments $\left(\mathrm{F}_{4,36}=187.42, \mathrm{P}<0.001\right)$ and trap catches were dose-dependent with more male $H$. marginata caught when higher pheromone loadings were used (Figure 5A). Log mean catch plotted against log pheromone loading indicated a linear association (Figure 5B).

Experiment 5 - Comparison with other traps. Substantially more male $H$. marginata were caught in the pheromone trap compared with both the unbaited sticky and water traps. During the trapping period of 18 days with six replicates, over $6500 \mathrm{H}$. marginata were caught using the pheromone traps compared with 26 and 27 in the sticky and water traps, respectively.

\section{Discussion}

Although Censier et al. $(2014,2016 a)$ identified the major component of the sex pheromone produced by female $H$. marginata as $(R)$-2-nonyl butyrate, they only tested the racemic compound in field trapping tests. The racemic compound was reported to be attractive to male $H$. marginata, but the effects of potential minor pheromone components detected were not investigated. Initial studies (Censier et al., 2014) used $20 \mathrm{mg}$ of the racemic compound in polyethylene sachet dispensers with a short field life of several days, and subsequently a rubber septum loaded with $5 \mathrm{mg}$ of the racemic compound was recommended for monitoring (Censier et al., 2016a).

Here, we confirmed that virgin female $H$. marginata produce $(R)$-2-nonyl butyrate with trace amounts (ca. $2 \%$
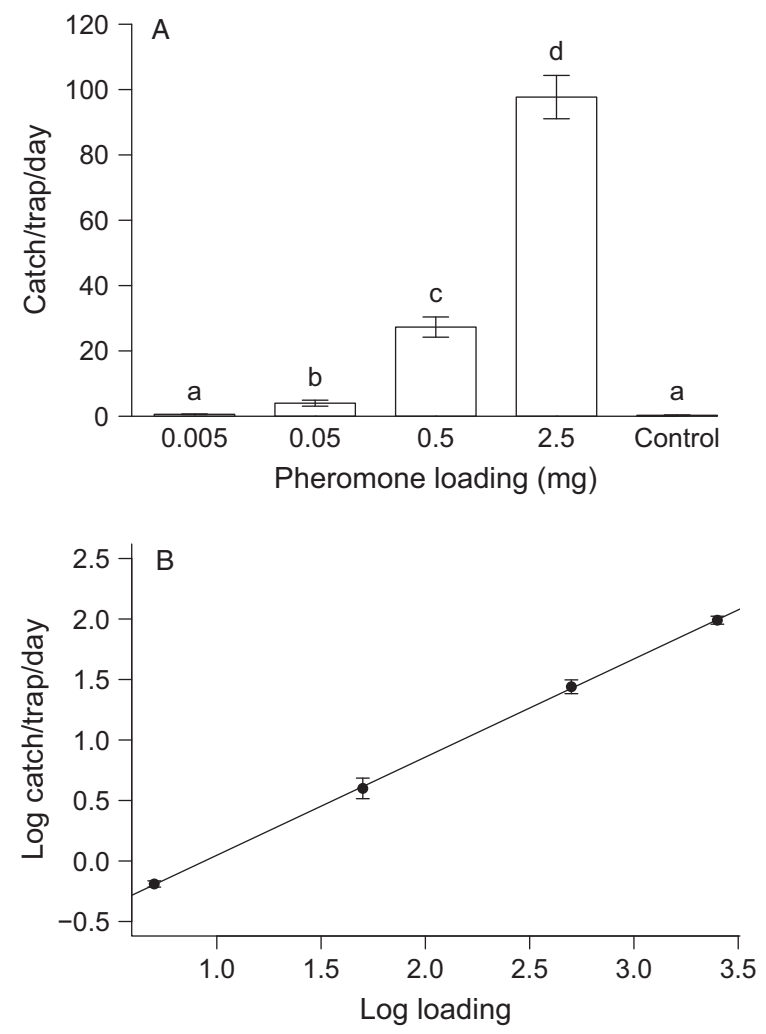

Figure 5 (A) Mean ( \pm SEM) catches of male Haplodiplosis marginata in experiment 4 with different lure loadings of $(R)$-2nonyl butyrate and unbaited control (2-11 June 2015; bars show back-transformed means). Means capped with different letters are significantly different (LSD test: $\mathrm{P}<0.05$ ). (B) Log mean daily catch per trap of $H$. marginata against log pheromone loading in experiment 4 .

relative to the major component) of 2-heptyl butyrate and 2-nonanol. The former two compounds elicited EAG responses from male $H$. marginata, but the latter did not. Censier et al. (2014) reported relatively large amounts of 2-nonanol were detected in volatiles from crushed pheromone glands, presumably due to enzymatic hydrolysis of the butyrate ester (cf. Ho \& Millar, 2002). In field tests, traps baited with $(R)$-2-nonyl butyrate caught more than $10 \times$ the numbers of male $H$. marginata caught in those baited with an equivalent amount of the racemic compound. The (S)-enantiomer was unattractive, but clearly has an antagonistic effect on the attractiveness of the $(R)$-enantiomer.

Absolute configuration is often important in the bioactivity of pheromones (Mori, 2007). The sex pheromone components of cecidomyiid midges identified so far all have one or two chiral centres and the females have been shown or are deduced to produce one stereoisomer (Hall 
et al., 2012). In components with two chiral centres the correct chirality is invariably critical for attraction. However, in the majority of those with one chiral centre the females produce one enantiomer that is attractive to males but the other enantiomer is neither attractive nor interferes with attraction of the active enantiomer (Hall et al., 2012). Haplodiplosis marginata is an exception to this trend with the $(S)$-enantiomer not only being unattractive but also reducing the attractiveness of the naturally produced $(R)$-enantiomer.

$(R)$-2-Nonyl butyrate is the simplest midge pheromone reported to date, having an unbranched carbon chain with an odd number of carbon atoms and the characteristic oxygenated functionality at the C-2 (Hall et al., 2012). 2-Nonanol and its esters are relatively easily resolved into the two enantiomers with high enantiomeric excess by kinetic hydrolytic resolution with a lipase enzyme (Hall et al., 2012). The extra cost involved in using ( $R$ )-2-nonyl butyrate in lures rather than the racemate would probably be outweighed by the more than 10-fold increase in catches, given that the cost of the active ingredient would be a small part of the overall cost of a commercially produced lure.

The absence of any effect of the potential minor pheromone components on attractiveness of the major component was somewhat surprising, although the sex pheromones of many of the cecidomyiid midge species identified to date consist of a single component (Hall et al., 2012). In the chrysanthemum midge, Rhopalomyia longicauda Sato et al., the sex pheromone is $(2 S, 8 Z)-2$ butyroxy-8-heptadecene, and addition of even $2 \%$ of the corresponding alcohol reduces attractiveness significantly (Liu et al., 2009).

Polyethylene vials and rubber septa were compared as commercially available, practical pheromone dispensers. These were equally effective in field trapping tests and were still attractive after 5 weeks in the field in the UK. However, laboratory tests indicated release from the vials was more uniform than from the septa and the former were likely to last longer in the field. The flight period of H. marginata can extend to up to 10 weeks (Censier et al., 2015), and the emergence pattern appears to show small peaks of activity throughout the season, coinciding with growth stages of the crop. The longevity of the lure must therefore allow for the monitoring period to extend over this period. After 6 weeks in the field polyethylene vials still contained over $40 \%$ of the pheromone originally loaded, but the longevity of the lures under field conditions remains to be tested in order to determine the need for lure renewal over entire the $H$. marginata flight period.

Increasing the loading of $(R)$-2-nonyl butyrate in polyethylene vial dispensers increased catches of male
$H$. marginata with a positive linear association between log mean catch and log pheromone dose over the range tested from 0.05 to $2.5 \mathrm{mg}$. This is useful in estimating the amount of pheromone required for monitoring purposes. Cross \& Hall (2009) determined that a mean daily catch of 25 midges per trap was suitable for monitoring apple leaf midge, Dasineura mali (Kieffer). The catch rate will inevitably vary greatly depending on the background population and time of trapping, but during the period of this experiment a loading of $0.5 \mathrm{mg}$ of $(R)$-2-nonyl butyrate gave a mean daily catch rate of 27.3 midges per trap. These data were obtained mid-season and therefore did not represent the peak catch rate which appears to occur soon after the start of emergence (Censier et al., 2016a,b). The higher loading of $2.5 \mathrm{mg}$ would therefore be unsuitable for monitoring in many field situations as traps would quickly become saturated. Meanwhile the lower loading of $0.05 \mathrm{mg}$, although still effective during this experiment, may not be sensitive enough to detect early emergence if there are fewer males around.

The higher loadings of pheromone may be appropriate if the lures are to be used for control of the pest by mass trapping or lure-and-kill approaches when the maximum catch is required. Use of $(R)$-2-nonyl butyrate rather than the racemic compound might also be advantageous in these situations. For example, a lure containing $2.5 \mathrm{mg}$ of the $(R)$-enantiomer would be equivalent in attractiveness to one containing $50 \mathrm{mg}$ of the racemic compound, and this latter loading would be above the capacity of the dispensers used here.

The pheromone has a limitation in that it only monitors male activity and females are rarely caught. This is the same with other successful pheromone trapping systems currently in use for monitoring cecidomyiid pests such as S. mosellana (Bruce et al., 2007). However, unlike S. mosellana where females disperse after mating, there is little evidence for female dispersal in $H$. marginata. Skuhravý et al. (1983) observed that females made several short flights until a suitable host plant was found. The same study also recorded a sex ratio of females to males of 59:41 and 54:46 based on emergence trap and Möricke trap catches, respectively. Female numbers are therefore likely to be slightly higher than, or comparable to, the number of males being caught. In practice, the enhanced performance of these pheromone traps in comparison to existing methods for trapping cecidomyiids far outweighs this limitation.

The present study indicates that a polyethylene vial loaded with $0.5 \mathrm{mg}$ of $(R)$-2-nonyl butyrate is a suitable lure for trapping adult $H$. marginata in the field, and would be equivalent in attractiveness to a lure containing $10 \mathrm{mg}$ of the racemic compound. This system will 
greatly improve detection in areas of low $H$. marginata populations, and will provide a greater degree of accuracy when monitoring for the start of adult activity. Further work is required to confirm the longevity of the lure under field conditions and to establish the relationship between trap catches and crop damage in order to provide a threshold above which treatments should be applied.

\section{Acknowledgements}

The authors are grateful to AHDB Cereals \& Oilseeds for funding this work (project number 214-0002) and to the farmers for the use of their land for field trials.

\section{References}

Basedow T (1986) Die Abundanzdynamik der Sattelmücke, Haplodiplosis marginata (von Roser) (Dipt., Cecidomyiidae), bei Fruchtwechsel, bei wiederholtem und bei permanentem Anbau von Weizen. Journal of Applied Entomology 102: 11-19.

Berry PM, Spink JH, Griffin JM, Sylvester-Bradley R, Baker CJ et al. (1998) Research to Understand, Predict and Control Factors Affecting Lodging in Wheat. Final Report Project 169. Home-Grown Cereals Authority, London, UK.

Bruce TJ \& Smart LE (2009) Orange wheat blossom midge, Sitodiplosis mosellana, management. Outlooks on Pest Management 20: 89-92.

Bruce TJ, Hooper AM, Ireland L, Jones OT, Martin JL et al. (2007) Development of a pheromone trap monitoring system for orange wheat blossom midge, Sitodiplosis mosellana, in the UK. Pest Management Science 63: 49-56.

Censier F, Fischer CY, Chavalle S, Heuskin S, Fauconnier M-L et al. (2014) Identification of 1-methyloctyl butanoate as the major sex pheromone component from females of the saddle gall midge, Haplodiplosis marginata (Diptera: Cecidomyiidae). Chemoecology 24: 243-251.

Censier F, de Proft M \& Bodson B (2015) The saddle gall midge, Haplodiplosis marginata (von Roser) (Diptera: Cecidomyiidae): population dynamics and integrated management. Crop Protection 78: 137-145.

Censier F, Heuskin S, San Martin y Gomez G, Michels F, Fauconnier M-L et al. (2016a) A pheromone trap monitoring system for the saddle gall midge, Haplodiplosis marginata (von Roser) (Diptera: Cecidomyiidae). Crop Protection 80: 1-6.

Censier F, Chavalle S, San Martin y Gomez G, de Proft M \& Bodson B (2016b) Targeted control of the saddle gall midge, Haplodiplosis marginata (von Roser) (Diptera: Cecidomyiidae), and the benefits of good control of this pest to winter wheat yield. Pest Management Science 72: 731-737.

Cork A, Beevor PS, Gough AJE \& Hall DR (1990) Gas chromatography linked to electroantennography: a versatile technique for identifying insect semiochemicals. Chromatography and Isolation of Insect Hormones and Pheromones (ed. by AR
McCaffery \& ID Wilson), pp. 271-279. Plenum Press, New York, NY, USA.

Cross JV \& Hall DR (2009) Exploitation of the sex pheromone of apple leaf midge Dasineura mali Kieffer (Diptera: Cecidomyiidae) for pest monitoring. Part 1. Development of lure and trap. Crop Protection 28: 139-144.

Dewar A (2012) Ecology and Control of Saddle Gall Midge, Haplodiplosis marginata von Roser (Diptera; Cecidomyiidae). Research Review 76 for AHDB-HGCA, Home-Grown Cereals Authority, Stoneleigh Park, UK.

Ellis SA, Ashlee NJ \& Maulden KA (2014) Improving risk assessment and control of saddle gall midge (Haplodiplosis marginata). Aspects of Applied Biology 127: 24-29.

Golightly WH \& Woodville HC (1974) Studies of recent outbreaks of saddle gall midge. Annals of Applied Biology 77: 97-101.

Gratwick M (1992) Saddle gall midge. Crop Pests in the UK: Collected Edition of MAFF Leaflets (ed. by M Gratwick), pp. 306309. Springer, Dordrecht, The Netherlands.

Gries R, Gries G, Khaskin G, King S, Olfert O et al. (2000) Sex pheromone of orange wheat blossom midge, Sitodiplosis mosellana. Naturwissenschaften 87: 450-454.

Hall DR, Amarawardana L, Cross JV, Francke W, Boddum $\mathrm{T}$ \& Hillbur Y (2012) The chemical ecology of cecidomyiid midges (Diptera: Cecidomyiidae). Journal of Chemical Ecology 38: 2-22.

Hardie J \& Minks AK (1999) Pheromones of Non-Lepidopteran Insects Associated with Agricultural Plants. CABI Publishing, Wallingford, UK.

Harris KM (1966) Gall midge genera of economic importance (Diptera: Cecidomyiidae). Part 1: introduction and subfamily Cecidomyiinae; supertribe Cecidomyiidi. Transactions of the Royal Entomological Society of London 118: 313-358.

Harris KM \& Foster S (1999) Gall midges. Pheromones of NonLepidopteran Insects Associated with Agricultural Plants (ed. by J Hardie \& AK Minks), pp. 27-49. CABI Publishing, Wallingford, UK.

Ho HY \& Millar JG (2002) Identification, electroantennogram screening, and field bioassays of volatile chemicals from Lygus hesperus Knight (Heteroptera: Miridae). Zoological Studies 41: 311-320.

Jones OT (1998) Practical applications of pheromones and other semiochemicals. Insect Pheromones and their Use in Pest Management (ed. by PE Howse, IDR Stevens \& OT Jones), pp. 261-355. Chapman and Hall, London, UK.

Liu Y, He X-K, Hall D, Farman D, Amarawardana L et al. (2009) (2S,8Z)-2-Butyroxy-8-heptadecene: major component of the sex pheromone of chrysanthemum gall midge, Rhopalomyia longicauda. Journal of Chemical Ecology 35: 715-723.

Mori K (2007) Significance of chirality in pheromone science. Bioorganic \& Medicinal Chemistry 15: 7505-7523.

Neises B \& Steglich W (1978) Simple method for the esterification of carboxylic acids. Angewandte Chemie International Edition 17: 523-525.

Nijveldt WC \& Hulshoff AJA (1968) Waarnemingen inzake de tarwestengelgalmug (Haplodiplosis equestris Wagner) in 
Nederland. Centrum voor Landbouwpublikaties en Landbouwdocumentatie, Wageningen, The Netherlands.

Oakley J \& Ellis S (2009) Orange Wheat Blossom Midge - Guidelines for Assessment and Control. Guide 45 (G45) for AHDBHGCA, Home-Grown Cereals Authority, Stoneleigh Park, UK.

Pope T \& Ellis S (2013) Monitoring Saddle Gall Midge (Haplodiplosis marginata) Larvae and Adult Emergence. Final report on Project Report 516 for AHDB-HGCA, Home-Grown Cereals Authority, Stoneleigh Park, UK.

R Core Team (2015) R: A Language and Environment for Statistical Computing. R Foundation for Statistical Computing, Vienna, Austria.

Skuhravý V, Skuhravá M \& Brewer WJ (1983) Ecology of the saddle gall midge Haplodiplosis marginata (von Roser) (Diptera,
Cecidomyiidae). Zeitschrift für Angewandte Entomologie 96: 476-490.

Skuhravý V, Skuhravá M \& Brewer TW (1993) The saddle gall midge Haplodiplosis marginata (Diptera: Cecidomyiidae) in Czech Republic and Slovak Republic from 1971-1989. Acta Societatis Zoologicae Bohemoslovacae 57: 117-137.

Witzgall P, Kirsch P \& Cork A (2010) Sex pheromones and their impact on pest management. Journal of Chemical Ecology 36: 80-100.

Woodville HC (1973) Observations on saddle gall midge (Haplodiplosis equestris (Wagn.)) in Eastern England. Plant Pathology 22: 177-181.

Zadoks JC, Chang TT \& Konzak CF (1974) A decimal code for the growth stages of cereals. Weed Research 14: 415-421. 